\title{
Adapting domestic product within cultural migration in Malaysia
}

\begin{abstract}
Planning one new product for the cultural migrating community, users determined needs may be particularly unpredictable in a changing society. The growth of products from abroad might overlook the diversity of users' culture. This shift is a challenge product planner and political experts. This paper illustrates how social researcher engaged in understanding about cultural migration and domestic product trend in Malaysia, where individuals, who find themselves in new environments, use and adapt household products to support both traditional and developing expectations. Findings from this work are beneficial to propose some principles of product migration in practice, and techniques for product planner and social scientist to developed a future product for a specific user to respond to these situations.
\end{abstract}

Keyword: Culture; Product; Migration; Traditional; Household 